Journal of Environmental
ISSN: $2525-815 \mathrm{X}$

\title{
Análise microbiológica da qualidade da água do povoado Barra Nova, Cocal de Telha - Piauí, Brasil
}

\section{Microbiological analysis of water quality from Barra Nova village, Cocal de Telha - Piauí, Brazil}

Francisco Emerson da Silva Brito ${ }^{a}$, Carla Adriana Rodrigues de Sousa Brito ${ }^{\mathrm{b}}$, Raniere Madeiros de Carvalho $^{\mathrm{b}}$, Thais Yumi Shinya ${ }^{\mathrm{a}}$

${ }^{a}$ Universidade Estadual do Piauí-UESPI, campus Heróis do Jenipapo, Av. Santo Antônio S/N, São Luís, Campo Maior, Piauí, Brasil. CEP: 64280-000. E-mail: emersonbritosilva@gmail.com, shinya.thais@cpm.uespi.br.

${ }^{\text {b }}$ Universidade Federal do Piauí-UFPI, campus universitário Ministro Petrônio Portella, Ininga, Teresina, Piauí, Brasil. CEP: 64049-550. E-mail: drina.bio@gmail.com, ranierecarvalho@yahoo.com.br.

\section{AR T I CLE I N F O}

Recebido 05 Jun 2020

Aceito 23 Abr 2021

Publicado 26 Jul 2021

\begin{abstract}
A B S T R A C T
Water is a natural resource and fundamental to Earth's biodiversity that has been suffering intense degradation and pollution in the last years depending on its parameters to be available for human utilization. The study aimed to analyze the microbiological quality of the water from Barra Nova village, Cocal de Telha - State of Piauí, Brazil, by collecting samples from well and four residences during May to August 2019, to compare the results with the information Water Distribution System administration of the village, and lastly realizing a survey of the history of the water's quality during the period of January 2018 to April 2019. The test Colilert ${ }^{\circledR}$ was used to analyze water samples and internal data from the administration of the Water Distribution System to formulate the history of water's quality featuring this study as quali-quantitative research. The results suggested the village's water was not appropriated to humans consume during the execution of this study and was found divergences between the present results and the data presented by the village's Water Distribution Administration. As for the water's quality historical, it was observed that the lack of complete reports for the solicited period and the absence of actions to correct the water's quality. As final impressions, the objectives were reached, and the data collected should be contributed to the improvement of the village's water quality. Keywords: Potability, bacteriological analysis, underground water.
\end{abstract}

\footnotetext{
R E S U M O

A água é um recurso natural e fundamental para a existência da biodiversidade na Terra que, nos últimos anos, tem sofrido uma intensa degradação e poluição, dependendo de uma análise de seus parâmetros para ser liberada para consumo humano. $\mathrm{O}$ estudo objetivou analisar a qualidade microbiológica da água do povoado Barra Nova, Cocal de Telha - Piauí no período de maio a agosto de 2019; comparar os resultados com os dados da administração do Sistema de Distribuição de Águas (SDA) que atende o povoado e, por fim, realizar um levantamento do histórico de qualidade da água nos períodos retroativos de janeiro de 2018 a abril de 2019. Foi utilizado o teste Colilert ${ }^{\circledR}$ para a análise das amostras de água e arquivos internos da administração do SDA para a formulação do histórico, caracterizando o estudo como uma pesquisa qualiquantitativa. Os resultados obtidos sugeriram que a água do povoado estava imprópria para consumo no período de execução do estudo e que houve divergência entre os resultados obtidos e os dados apresentados pela empresa responsável pelo SDA do povoado. Quanto ao histórico de qualidade, foi observada uma ausência de relatórios completos para o período solicitado e que não foram tomadas medidas eficientes para a correção da qualidade da água. Como impressão final, os objetivos foram atingidos e os resultados e dados apresentados devem ser utilizados para contribuir para a melhoria da qualidade da água do povoado.
} 


\section{Introdução}

As águas têm apresentado uma intensa degradação causada por ações insustentáveis como, por exemplo, o despejo de esgotos residenciais e excremento de animais sem tratamento, que se infiltram no solo e acabam atingindo os lençóis freáticos e os reservatórios subterrâneos, influenciando negativamente na qualidade desse líquido tão importante para a vida (Mirlean et al., 2005; Saling et al., 2017).

Mesmo que a sua aparência esteja satisfatória, incolor, sem turvações e cheiro, ela ainda pode estar inadequada para utilização, dependendo assim de uma análise de seus parâmetros físicos, químicos e biológicos para que seja liberada para o consumo humano. Quando a água não recebe os tratamentos adequados e sua potabilidade não é avaliada corretamente, microorganismos podem acabar se proliferando, promovendo o aparecimento de várias doenças graves de origem hídrica, como a febre tifoide, transmitida pela Salmonella enterica sorovar typhi, que tem relação com as bactérias entéricas como Escherichia coli. Sua dispersão pode ocorrer por fezes contaminadas que atingem os lençóis freáticos e posteriormente os sistemas de distribuição de águas (Madigan et al., 2016).

Além dos vários organismos bióticos que podem estar presentes em águas que não recebem o tratamento adequado, há também compostos químicos como chumbo, níquel, cobre, mercúrio e vários outros, que ao serem absorvidos pelo sistema digestivo humano causam efeitos tóxicos que podem se expressar de forma aguda ou crônica (Brasil, 2017; Freitas, Brilhante \& Almeida, 2001). Todos esses poluentes dispostos de maneira inadequada sobre o solo acabam contaminando e atingindo os recursos hídricos, como os reservatórios subterrâneos e os sistemas de distribuição de águas, alcançando, por conseguinte os homens, os outros animais e as plantas (Oliveira $\&$ Pasqual, 2004). Para ser considerada segura para utilização e consumo, as águas devem passar por análises de seus parâmetros físicos, químicos e microbiológicos a fim de ser classificada com o status de potável, quando está em acordo com os padrões estabelecidos (Brasil, 2017). Cada país determina os seus próprios padrões de qualidade das águas, sendo que no Brasil esse padrão é determinado pelo Anexo XX da Portaria de Consolidação No 05/2017 do Ministério da Saúde (Brasil, 2017). Além do padrão, o anexo da portaria atribui competências e responsabilidades específicas para cada segmento organizacional, com o objetivo de se fazer executar o disposto na resolução. A nível municipal, o responsável pela distribuição de águas, que pode ser uma empresa pública ou privada, deve garantir o controle da qualidade física, química e microbiológica das águas, enquanto as Secretarias Municipais de Saúde devem acompanhar todo o processo, inspecionando o controle de qualidade, a distribuição e as práticas operacionais adotadas, notificando o responsável pela distribuição sempre que houver irregularidades (Brasil, 2017).

Quanto ao controle da qualidade microbiológica recorre-se à identificação dos organismos indicadores de contaminação, a saber, coliformes totais e coliformes termotolerantes e seus respectivos valores máximos permitidos (VMP) que, quando presente em amostras de água, indicam uma grande possibilidade de transmissão de patogenias (Lacerda, Räder \& Lopes, 2019; Madigan et al., 2016; Saling et al., 2017).

Os coliformes totais são definidos pela Fundação Nacional de Saúde como bacilos gramnegativos, dependentes ou não da presença de oxigênio, não formadores de esporos, oxidase negativos, capazes de se desenvolverem na presença de sais biliares ou agentes tensoativos que fermentam a lactose e geram como produtos finais ácidos, gases e aldeídos, sendo utilizados para indicar a eficiência do tratamento de água e integridade do sistema de distribuição de águas (Ministério da Saúde, 2013a; Brasil, 2017).

Os coliformes termotolerantes são definidos como um subgrupo de bactérias com quase todas as características dos coliformes totais (bacilares, gram negativas, aeróbias ou facultativas, não formadoras de esporos), com exceção da fermentação da lactose, que neste grupo ocorre a uma temperatura de $44,5 \pm 0,2^{\circ} \mathrm{C}$ em 24 horas. A principal representante deste subgrupo é a E. coli, bactéria de origem exclusivamente fecal indicadora de contaminação recente e eventual presença de outros organismos patógenos em amostras de águas (Ministério da Saúde, 2013a; Madigan et al., 2016).

Além disso, quando presente fora do intestino, a E. coli pode agir de forma oportunista em órgãos e tecidos normalmente estéreis, causando doenças com a meningite e infecções urinárias e pulmonares, além de comporta-se como um patógeno bastante especializado quando fora do seu habitat normal, causando doenças mesmo em hospedeiros sadios (Tortora, Funke \& Case, 2017).

Diante do exposto, o desenvolvimento deste estudo foi dado por meio da relação entre a qualidade das águas destinadas ao consumo humano e a saúde no município de Cocal de Telha 
- Piauí, sendo um estudo pioneiro no que diz respeito às análises microbiológicas para a água e pela agregação de conhecimento científico sobre a região. Espera-se que a execução deste estudo sirva de apoio para o desenvolvimento de projetos futuros relacionados à qualidade da água no município e que a administração do sistema de distribuição execute ações corretivas e efetivas que melhorem a qualidade deste líquido visando um desenvolvimento integral do povoado. Assim sendo, o objetivo deste estudo foi analisar a presença de coliformes totais e termotolerantes na água do povoado Barra Nova no município de Cocal de Telha - Piauí, e realizar um levantamento do histórico da qualidade microbiológica para os anos de janeiro de 2018 a abril de 2019 junto à empresa responsável pela distribuição de águas no local.

\section{Material e Métodos}

Área de estudo

O município de Cocal de Telha está situado na mesorregião centro-norte piauiense, a $114 \mathrm{~km}$ da capital do Estado do Piaú, Teresina. Tem coordenadas $04^{\circ} 33^{\prime} 19^{\prime \prime} \mathrm{S}, 41^{\circ} 58^{\prime} 20^{\prime \prime} \mathrm{W}$, altitude de $140 \mathrm{~m}$ e uma população total de 4.525 pessoas de acordo com o censo de 2010, segundo o Instituto Brasileiro de Geografia e Estatística (Brasil, 2019).

O povoado Barra Nova é parte integrante do município, localizado em uma região próxima à cidade (entre um e dois quilômetros) com fácil acesso. Informações verbais recebidas da Secretaria Municipal de Saúde de Cocal de Telha em outubro de 2019 mostravam que a ocupação da área do povoado estava formada por 11 famílias e, portanto, 11 residências com moradores de diversas idades (desde crianças de colo a idosos), totalizando uma população de 35 pessoas.

A distribuição de águas do povoado ocorre por meio de um chafariz. As águas são captadas do poço tubular por uma bomba que a canaliza diretamente para um reservatório que a distribui posteriormente para as residências (Figura 1). O Sistema de Distribuição de Águas (SDA) é considerado do tipo fechado, pois a água é distribuída exclusivamente para o povoado, não estando interligado a nem um SDA de outros povoados ou bairros da cidade.

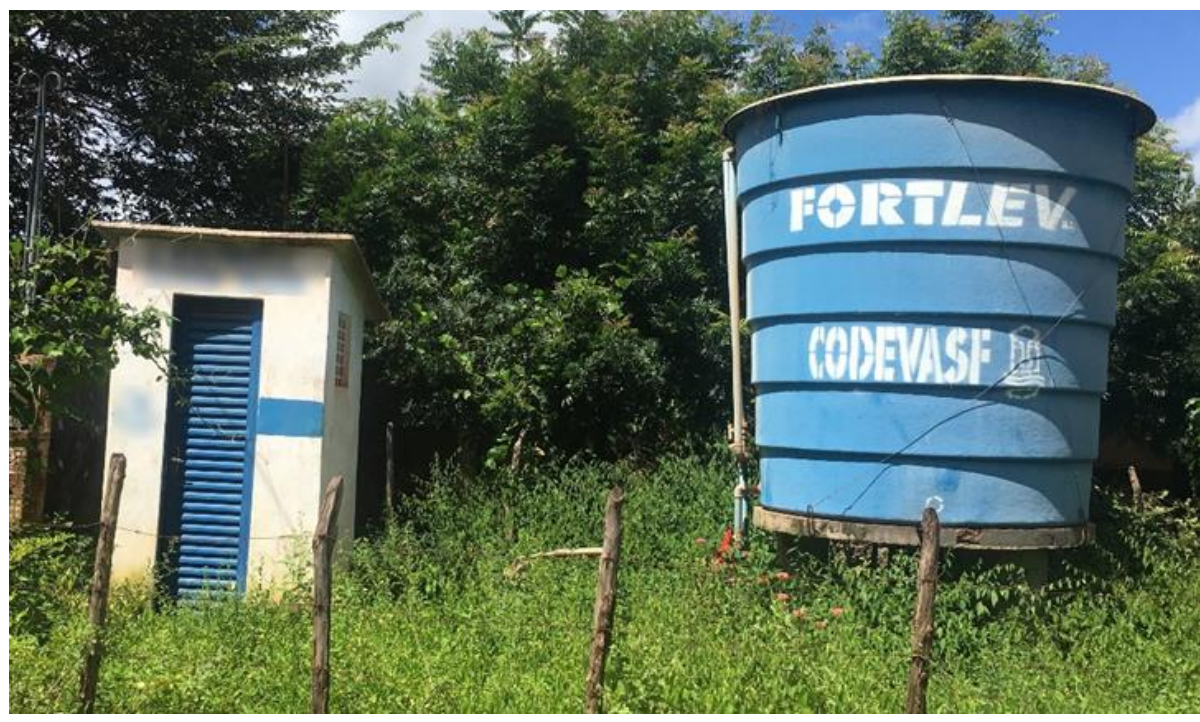

Figura 1. Chafariz do povoado Barra Nova, Cocal de Telha (PI) com o centro de operação da bomba d'água a esquerda e o reservatório de água a direita, e centralizado entre ambos, o poço tubular. Fonte: Brito et al. (2019).

\section{Obtenção das amostras}

Foram coletadas nos meses de maio, junho, julho e agosto de 2019 um total de 20 amostras de água provenientes do chafariz do povoado. Em cada um dos meses foram realizadas cinco coletas, sendo quatro das torneiras das cozinhas das residências e uma do reservatório de água do povoado. $\mathrm{O}$ critério de escolha das residências se deu pela proximidade em relação ao chafariz e a distribuição delas no povoado, de modo que se obtivesse amostras de todo o SDA. As coletas ocorreram sempre nos mesmos pontos com o intuito de montar um histórico que permitiu comparar os dados qualitativos das amostras de um mês para o outro.

A coleta deu-se conforme o descrito no Manual de orientações técnicas para coleta, acondicionamento e transporte de amostras de água para consumo humano do Ministério da Saúde (2013b). O armazenamento ocorreu com o uso de sacos tipo Whirl-pak com as devidas identificações (data, hora e local de coleta) previamente anotadas. As torneiras foram desinfetadas com o uso de álcool 70\% (v/v), sendo vazão da água baixa com 
fluxo controlado até totalizar $130 \mathrm{~mL}$. Após as coletas, os sacos Whirl-pak foram acondicionados em uma caixa térmica com gelo e lacrada com fita adesiva ao final do procedimento para que as amostras ficassem conservadas durante $o$ transporte.

\section{Análise das amostras}

Após cada coleta as amostras foram encaminhadas para o Laboratório de Microbiologia do Departamento de Parasitologia e Imunologia da Universidade Federal do Piauí (UFPI), campus Ministro Petrônio Portela. Todas as amostras foram analisadas em, no máximo, cinco horas após as coletas.

A determinação de coliformes totais e coliformes termotolerantes foi realizada utilizando os testes Colilert ${ }^{\circledR}$ recomendados pelo Standard
Methods for Examination of Water and Wastewater da American Public Health Association (APHA, 2017, part. 9223b, p. 2) com metodologia descrita a seguir. As amostras foram homogeneizadas ainda dentro dos sacos Whirl-pak. Uma alíquota de $100 \mathrm{~mL}$ de cada amostra foi retirada e alocada em um frasco Erlenmeyer estéril identificado, sendo adicionada uma ampola com o substrato $\quad$ Colilert $^{\circledR} \quad$ (Figura 2). Após homogeneização dos frascos, todos foram incubados em estufa a $35^{\circ} \mathrm{C} \pm 1{ }^{\circ} \mathrm{C}$ por $24 \mathrm{~h}$. Para controle positivo foi usado $100 \mathrm{~mL}$ de água sem cloro adicionada de Escherichia coli, e como controle negativo foi utilizado $100 \mathrm{~mL}$ de água destilada estéril. Todo o manuseio ocorreu em ambiente estéril, utilizando bico de Bunsen e álcool $70 \%(\mathrm{v} / \mathrm{v})$.

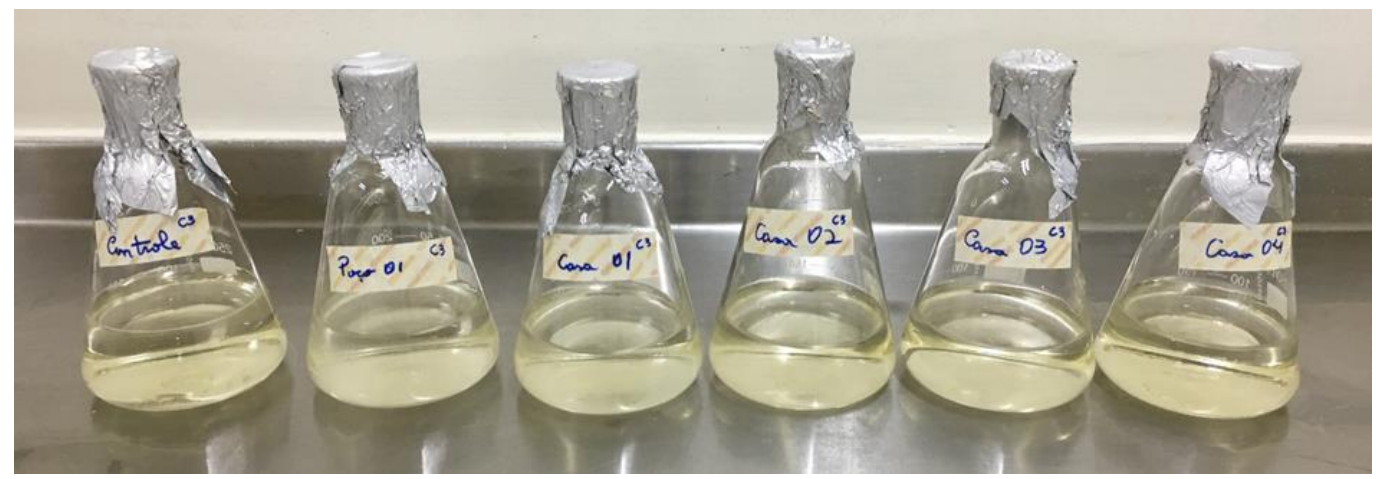

Figura 2. Amostras de água coletadas no período de julho de 2019 no povoado Barra Nova, em Cocal de Telha (PI), homogeneizadas com Colilert ${ }^{\circledR}$. Fonte: Brito et al. (2019).

Passado o período de incubação de 24 h os frascos que apresentaram a água com coloração amarelo foram considerados positivos (presença) para coliformes totais. Para os frascos onde a água se manteve incolor aguardou-se mais $24 \mathrm{~h}$ nas mesmas condições para comprovação da coloração (Figura 3) (American Public Health Association,
2017, part. 9223b, p. 3). As amostras que permaneceram incolores após $48 \mathrm{~h}$ de incubação foram consideradas negativas para coliformes totais e coliformes termotolerantes, e as que apresentaram coloração amarelada foram invalidadas (American Public Health Association, 2017, part. 9223b, p. 3).

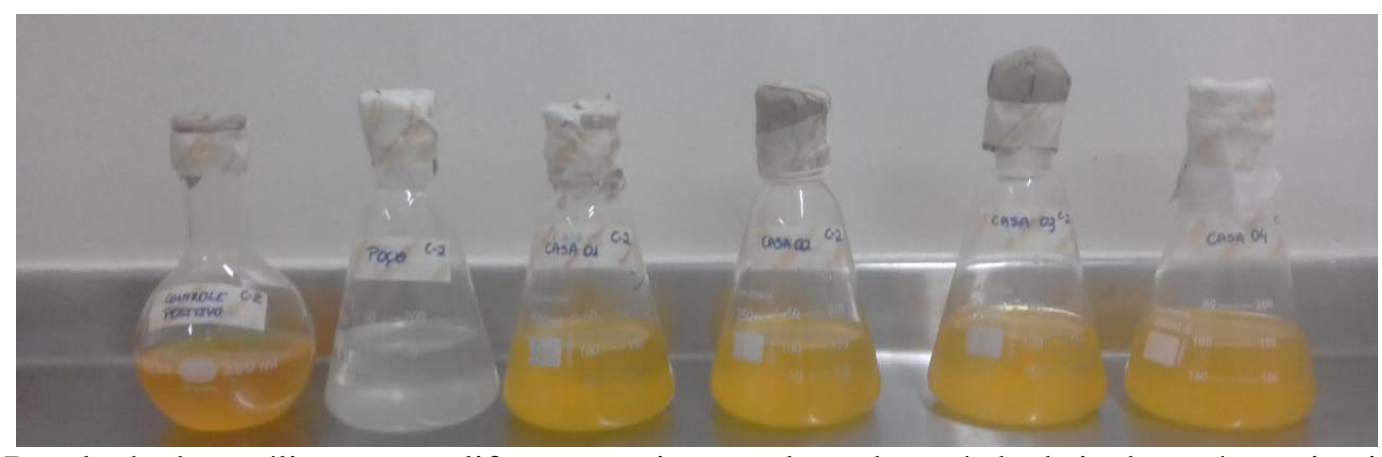

Figura 3. Resultado das análises para coliformes totais nas coletas do período de junho após o primeiro período de incubação. Fonte: Brito et al. (2019).

A alteração na coloração quando há presença de coliformes totais acontece porque o Colilert $^{\circledR}$ possui os substratos ONPG (Ortonitrofenil- $\beta$-galactopiranosídeo) e MUG (4-
Metilumbeliferil) como fontes de carbono. O ONPG é metabolizado pelas enzimas $\beta$ galactosidase dos coliformes totais, que altera a coloração do meio para amarelada. Por sua vez, as 
$\beta$-glucuronidase da E. coli metaboliza o MUG, gerando uma fluorescência azul na presença de luz ultravioleta (American Public Health Association, 2017, part. 9223b, p. 3; Ministério da Saúde, 2013a; Godinho, 2010; Idexx Brasil, 2019).

\section{Levantamento do histórico de qualidade}

O Anexo XX da PCR No 05/2017 do Ministério da Saúde (Brasil, 2017) determina que a empresa responsável pela distribuição de águas, após a realização dos testes laboratoriais de análises, registre os resultados e tornem-no disponíveis para consulta pública a qualquer momento. Com base na legislação mencionada foi solicitado a administração do sistema de distribuição de águas do povoado os registros das análises realizadas de janeiro de 2018 a abril de 2019 para que, utilizando-se dessas informações, fosse montado o Histórico de Qualidade do período para posterior comparação com os resultados do presente estudo.

\section{Resultados e Discussão}

Todas as amostras coletadas confirmaram a presença de coliformes totais (Tabela 1) independente do ponto de coleta utilizado: seja saída do reservatório de água ou rede interna das residências. De modo semelhante, não importou o turno das coletas nem a época coletada (maio, junho, julho ou agosto). Resultados similares a estes foram encontrados por Saling et al. (2017) e Silva, Barbosa \& Silva (2017), quando analisaram a água de poços dos municípios de Colinas (RS) e Carmo do Rio Verde (GO), respectivamente, e detectaram a presença de coliformes totais em todas as amostras válidas.

Tabela 1. Presença ou ausência de coliformes totais para as amostras de água coletadas no povoado Barra Nova, Cocal de Telha (PI). Fonte: Brito et al. (2019).

\begin{tabular}{llllccc}
\hline Coleta & Turno & SRA01 & R01 & R02 & R03 & R04 \\
\hline 02 de maio & Tarde & Presença & Presença & Presença & Presença & Presença \\
13 de junho & Manhã & Inválido & Presença & Presença & Presença & Presença \\
17 de julho & Manhã & Presença & Presença & Presença & Presença & Presença \\
27 de agosto & Manhã & Presença & Presença & Presença & Presença & Presença \\
\hline
\end{tabular}

SRA = saída do reservatório de água como ponto de coleta; $\mathrm{R}=$ residência como ponto de coleta; Inválido = coloração da amostra com alteração após $\leq 48 \mathrm{~h}$ de incubação.

Com relação a análise para coliformes termotolerantes (Tabela 2), das 20 amostras coletadas durante o período de estudo, em $3(15 \%)$ foram confirmadas presença de E. coli. Uma foi detectada na saída do Sistema de Distribuição de Águas (SDA) na coleta do mês de julho e duas na rede interna das residências, sendo uma no mês de junho para a Residência 02 (R02) e uma outra no mês de agosto para a Residência 04 (R04). Souza et al. (2014) encontraram resultados semelhantes a estes quando analisaram a água de poços do município de Fernandópolis (SP) e detectaram que das 20 amostras coletadas, quatro (20\% do total) apresentavam presença de E. coli. Silva, Barbosa \& Silva (2017) encontraram resultados superiores aos apresentados neste estudo, quando coletaram 10 amostras de água de poços do município de Carmo do Rio Verde (GO) e 50\% (cinco amostras) delas apresentaram a presença de E. coli.

Tabela 2. Presença ou ausência de coliformes termotolerantes para as amostras de água coletadas no povoado Barra Nova, Cocal de Telha (PI). Fonte: Brito et al. (2019).

\begin{tabular}{llllllc}
\hline Coleta & Turno & SRA01 & R01 & R02 & R03 & R04 \\
\hline 02 de maio & Tarde & Ausência & Ausência & Ausência & Ausência & Ausência \\
13 de junho & Manhã & Invalido & Ausência & Presença & Ausência & Ausência \\
17 de julho & Manhã & Presença & Ausência & Ausência & Ausência & Ausência \\
27 de agosto & Manhã & Ausência & Ausência & Ausência & Ausência & Presença \\
\hline
\end{tabular}

SRA = saída do reservatório de água como ponto de coleta; $\mathrm{R}=$ residência como ponto de coleta; Inválido = coloração da amostra com alteração após $\leq 48 \mathrm{~h}$ de incubação.

Considerando a presença de coliformes totais e coliformes termotolerantes (E. coli), Bezerra et al. (2017); Coelho et al. (2017); Silva et al. (2018a, 2018b); Zamilian, Paula \& Zamilian (2018) também encontraram resultados positivos nos mais diversos locais como comunidades, escolas e chafarizes distribuídos pelo Brasil. Em todos os estudos mencionados os autores concordam que a ausência de saneamento básico eficiente é a principal causa apontada quando se detecta os coliformes totais pois indicam que a água não passou por nenhum tratamento eficiente, enquanto a presença de coliformes termotolerantes indicam contaminação recente por fezes e 
possivelmente diversos outros patógenos, expondo a população que consome a água aos mais diversos riscos de saúde (Coelho et al., 2017; Zamilian, Paula \& Zamilian, 2018).

O pensamento dos autores supracitados vai de encontro à realidade do povoado, quando os dados da Secretaria Municipal de Saúde mostram que com relação ao escoamento da água dos banheiros residenciais, $54,5 \%$ das residências fazem o escoamento de maneira irregular, $9 \%$ de maneira regular e 36,5\% não informaram o tipo (informação verbal, 2019). Todo esse escoamento irregular se infiltra no solo, alcançando os lençóis freáticos e contaminando toda a água subterrânea existente na região. A problemática se agravou quando a população demonstrou não possuir boas instruções com relação à importância de se ter água de qualidade na residência no momento em que os dados da Secretaria de Saúde do município (informação verbal, 2019) mostraram que, das 11 residências do povoado, apenas 36,4\% fazem a filtração da água antes do consumo, 54,5\% não fazem o uso de nenhum tratamento de água (filtração, fervura e outros) antes do consumo e $9,1 \%$ não informaram se utilizam ou não algum tipo de tratamento. Por isso, o constante monitoramento da qualidade das águas de acesso direto a população, tanto pelo responsável pela distribuição quanto por meio das Secretarias de Saúde, se faz essencial para a promoção da saúde pública e conservação dos lençóis freáticos, melhorando assim a qualidade da água na região (Silva et al., 2018b).

As análises microbiológicas realizadas pela administração do sistema de distribuição de águas (SDA) do povoado pelo período de maio a agosto de 2019 estão expostas na Tabela 3.

Tabela 3. Análises microbiológicas para coliformes totais e coliformes termotolerantes do povoado Barra Nova, Cocal de Telha (PI), para o período de maio a agosto de 2019. Fonte: Arquivos da administração do SDA (2019).

\begin{tabular}{lccc}
\hline Coletas & Turno & Coliformes totais & Coliformes termotolerantes \\
\hline 14 de maio* & Tarde & - & - \\
junho & - & - & - \\
23 de julho & Tarde & Presença & Ausência \\
27 de agosto & Tarde & Presença & Ausência \\
\hline
\end{tabular}

- = Não há registros sobre a qualidade bacteriológica da água do povoado utilizado como área de estudo para o mês solicitado; * = análise não realizada por problemas técnicos segundo consta no relatório.

Comparando os resultados das análises deste estudo com os apresentados pela administração do SDA percebeu-se a ausência de informações mensais sobre a qualidade da água que é distribuída a população daquele povoado. Para os meses em que houve registro, os dados mostraram que ambos estão de acordo para a presença de coliformes totais, mas não para os termotolerantes. Como o laboratório que realizou as análises microbiológicas utilizou uma metodologia similar à utilizada neste estudo, por meio de substrato cromogênico/enzimático, a divergência nos resultados para E. coli pode ser explicada pelas formas de preservação e armazenamento das amostras após a coleta, segundo constava nos relatórios. O Manual de orientações técnicas para coleta, acondicionamento e transporte de amostras de água para consumo humano do Ministério da Saúde (2013b) que diz que as amostras devem ser acondicionadas em caixa térmica com gelo para preservação (entre $2^{\circ} \mathrm{C}$ e $8^{\circ} \mathrm{C}$ ), propiciando assim maior qualidade às amostras e maior confiabilidade aos resultados. Entretanto, segundo os relatórios dos laudos fornecidos pela administração, as amostras estavam acondicionadas em temperatura ambiente $\left(15^{\circ} \mathrm{C}\right.$ a $\left.30^{\circ} \mathrm{C}\right)$, contrariando as orientações do Ministério da Saúde, o que pode ter prejudicado os resultados. A divergência dos resultados também pode ter ocorrido pela baixa quantidade de amostragem, sendo necessárias mais replicatas dessas amostras, bem como algum erro de manuseamento durante os testes.

Quando comparada a variação presença/ausência da $E$. coli considerando os resultados das análises feitas por meio deste estudo com todas as disparidades de um mês para o outro e, ainda, entre um ponto de coleta e outro com os dados informados pela administração do SDA, deve-se levar em consideração que as propriedades físicas, químicas e microbiológicas da água sofrem variação dependendo das condições ambientais locais, como o aumento da temperatura durante o dia, por exemplo, além da possível presença de outros micro-organismos que poderiam entrar em competição com a $E$. coli, alterando a dinâmica dos micro-organismos, e influenciando diretamente no tempo de vida da bactéria, que fora do seu ambiente primário (o intestino de animais de sangue quente) é reduzido para quatro a 12 semanas (Comte et al., 2006; Edberg et al., 2000; Franco \& Landgraf, 
2008, p. 13; Thomaz, 1999). Diante deste fato, a variação entre ausência/presença observada pode ser justificada considerando que as bactérias presentes naquele ponto de coleta em específico sofreram redução no seu tempo de vida de um período de coleta para o outro e, por isso, não foram detectadas.

Entretanto, se faz necessário ressaltar que mesmo com a ausência temporária de E. coli em um mês ou ponto de coleta não significou que todo o SDA do povoado estivesse livre da bactéria no período de estudo, uma vez que ela poderia estar presente em outros locais que não foram utilizados como pontos de coleta, visto que não há meios sanitários eficientes e ativos no Sistema de Distribuição para combater os coliformes.

Para a construção do Histórico de Qualidade foi solicitado à administração do SDA os laudos das análises de água do povoado no período de janeiro de 2018 a abril de 2019 (Tabela 4).

Tabela 4. Qualidade microbiológica da água do povoado Barra Nova, Cocal de Telha (PI) para coliformes totais e coliformes termotolerantes no período de janeiro de 2018 a abril de 2019. Fonte: Administração do SDA do povoado (adaptado, 2019).

\begin{tabular}{lccc}
\hline Coletas & Turno & Coliformes totais & Coliformes termotolerantes \\
\hline 2018 & & & - \\
Janeiro & - & - & - \\
Fevereiro & - & - & - \\
Março & - & - & - \\
Abril & - & - & - \\
Maio & - & - & - \\
Junho & - & - & - \\
Julho & - & - & - \\
Agosto & - & - & - \\
Setembro & - & - & - \\
Outubro & - & - & Ausência \\
28 de novembro & Tarde & Ausência & Ausência \\
25 de dezembro & Tarde & Ausência & - \\
2019 & & & - \\
Janeiro & - & - & Ausência \\
Fevereiro & - & - & Ausência \\
26 de março & Tarde & Presença & Presença \\
23 de abril & Tarde & Parde & \\
\hline
\end{tabular}

- = Não há registros sobre a qualidade bacteriológica da água do povoado para o mês solicitado.

A partir do histórico é possível visualizar a ausência de informações documentadas que mostrem o status da qualidade da água em alguns períodos. Em 16 meses (janeiro de 2018 a abril de 2019) foram realizados quatro laudos de análises, sendo que dois apresentaram resultados insatisfatórios em sequência, o que pode levar a inferir que os resultados trazidos nestes documentos não foram considerados para a correção e ajustes da qualidade da água aos parâmetros legais desejados.

O mesmo problema foi encontrado quando solicitado os dados de maio a agosto de 2019, visualizando-se apenas a existência de laudos para os meses de julho e agosto. Além desse fato, a administração do SDA não faz análises da qualidade da água de acordo com o solicitado pela legislação vigente, sendo os laudos apresentados oriundos do Programa Nacional de Vigilância da Qualidade da Água para Consumo Humano (VIGIAGUA), vinculado à Secretaria Municipal de
Saúde, que tem como uma das funções fiscalizar a qualidade da água distribuída a população brasileira (Ministério da Saúde, 2005).

Todas as amostras apresentaram resultados que estão em desacordo com o Anexo XX da Portaria de Consolidação No 05/2017 do Ministério da Saúde, legislação vigente para a qualidade da água direcionada ao consumo humano. De acordo com o documento apenas uma amostra mensal pode ser positiva (presença) para coliformes totais quando coletada na rede de distribuição e nenhuma amostra pode ser positiva (presença) na saída do tratamento ou quando chega as residências se a população abastecida for inferior a 5.000 habitantes (Brasil, 2017), como é o caso do povoado.

Analisando os resultados como um todo observou-se que $100 \%$ das amostras coletadas por meio da execução deste estudo confirmaram presença de coliformes totais na rede de distribuição, chegando inclusive as residências dos 
moradores. Além disso, $15 \%$ das amostras coletadas confirmaram a presença de E. coli na água, sendo $10 \%$ nas torneiras das casas dos residentes, quando é determinado pelo Ministério da Saúde (MS) ausência em $100 \mathrm{~mL}$ de amostra tanto na saída do tratamento quanto na água para consumo humano.

Os relatórios apresentados pela administração do SDA e os que compõem o Histórico de Qualidade não mostraram dados suficientes para o controle da qualidade da água. De acordo com o Anexo 13 do Anexo XX da PRC $\mathrm{N}^{\circ}$ 05/2017 do MS, devem ser realizadas no mínimo 10 coletas mensais de amostras de água do Sistema de Distribuição, sendo duas semanais na saída do tratamento ou rede interna das residências para situações em que a população abastecida for inferior a 5.000 habitantes, como é o caso do povoado (Brasil, 2017). Entretanto, foram apresentadas apenas seis coletas para um período de 16 meses (janeiro de 2018 a abril de 2019 para o Histórico de Qualidade somado aos meses de maio a agosto, que foram os meses de execução deste estudo).

\section{Conclusão}

A água do povoado Barra Nova, Cocal de Telha - Piauí esteve imprópria para consumo no período de execução deste estudo (maio a agosto de 2019), com base nas análises deste estudo e das informações da própria administração do Sistema de Distribuição de Águas (SDA). É importante e necessário que ocorra um profundo debate com todos os envolvidos para que o acesso à água de qualidade seja garantido e que os lençóis freáticos de toda a região do município sejam preservados a médio e longo prazo, garantindo melhorias nas condições e qualidade de vida e, ainda, prevenindo a população do acometimento de doenças de origem hídrica.

\section{Referências}

American Public Health Association (APHA). 2017. Standard Methods for the Examination of Water and Wastewater. 23. ed. Washington, EUA.

Bezerra, A. D. A.; Nogueira, E. R.; Araújo, F. G. D. M.; Brandão, M. G. A.; Chaves, B. E.; Pantoja, L. D. M. 2017. Análise da potabilidade de água de chafarizes de dois bairros do município de Fortaleza, Ceará. Acta Biomedica Brasiliensia, 08, 01, 2017. https://doi.org/10.18571/acbm.119

Brasil. Panorama das Cidades@: Piauí, Cocal de Telha. Instituto Brasileiro de Geografia e Estatística. Disponível em: https://cidades.ibge.gov.br/brasil/pi/cocal-detelha/panorama. Acesso em: 3 maio 2019.

Brasil. Portaria de Consolidação $\mathrm{N}^{\circ} 5$, de 28 de setembro de 2017 (Anexo XX), Ministério da Saúde. Disponível em: https://portalarquivos2.saude.gov.br/images/ pdf/2018/marco/29/PRC-5-Portaria-deConsolida----o-n---5--de-28-de-setembro-de2017.pdf. Acesso em: 7 abr. 2019.

Coelho, S. C.; Duarte, A. N.; Amaral, L. S.; Santos, P. M. S.; Salles, M. J.; Santos, J. A. A.; Sotero-Martins, A. 2017. Monitoramento da água de poços como estratégia de avaliação sanitária em Comunidade Rural na Cidade de São Luís, MA, Brasil. Revista Ambiente e Agua, $\quad 12, \quad 1, \quad$ p. 156-167. https://doi.org/10.4136/ambi-agua.1962

Comte, J.; Jacquet, S.; Viboud, S. Fontvieille, D.; Millery, A.; Paolini, G.; Domaizon, I. 2006. Microbial Community Structure and Dynamics in the Largest Natural French Lake (Lake Bourget). Microbial Ecology, 52, 1, 72 89. https://doi.org/10.1007/s00248-0040230-4

Edberg, S. C.; Rice, E. W.; Karlin, R. J.; Allen, M. J. 2000. Escherichia coli: the best biological drinking water indicator for public health protection. Journal of Applied Microbiology, 88, S1, 106S-116S. https://doi.org/10.1111/j.13652672.2000.tb05338.x

Franco, B. D. G. M.; Landgraf, M. 2008. Microbiologia dos Alimentos. Atheneu, $1^{\mathrm{a}} \mathrm{ed}$, São Paulo. 196p.

Freitas, M. B.; Brilhante, O. M.; Almeida, L. M. 2001. Importância da análise de água para a saúde pública em duas regiões do Estado do Rio de Janeiro: enfoque para coliformes fecais, nitrato e alumínio. Cad. Saúde Pública, 17, 03, 651-660. http://dx.doi.org/10.1590/S0102311X2001000300019

Godinho, V. M. 2010. Investigação de bactérias patogênicas por técnicas moleculares em um sistema de tratamento de esgotos composto por reator UASB e lagoas de polimento. Tese de Doutorado, Universidade Federal de Minas Gerais. Belo Horizonte, Minas Gerais. 166p.

Idexx Brasil. Colilert. Disponível em: https://www.idexx.com.br/pt-br/water/waterproducts-services/colilert/. Acesso em: 3 set. 2019.

Lacerda, A. B.; Räder, A. S.; Lopes, E. S. 2019. A eficiência de remoção de coliformes em uma estação de tratamento de água convencional. 
Brazilian Journal of Development, 05, 06, 7523-7539.

Madigan, M. M.; Martinko, J. M.; Parker, J. 2016. Microbiologia de Brock. Artmed, 14 ${ }^{\mathrm{a}} \mathrm{ed}$, Porto Alegre. 986p.

Ministério da Saúde. 2005. Programa Nacional de Vigilância em Saúde Ambiental relacionada à qualidade da água para consumo humano. Brasília, DF.

Ministério da Saúde. 2013a. Manual Prático de Análise de Água. Editora Funasa, $4^{\mathrm{a}}$ ed, Brasília. 150p.

Ministério da Saúde. 2013b. Orientações técnicas para coleta, acondicionamento e transporte de amostras de água para consumo humano. Brasília, DF. Disponível em: http://portalarquivos2.saude.gov.br/images/p df/2014/julho/24/Proceds-e-progr-de-coletade---gua.pdf. Acesso em: 20 jul. 2019.

Mirlean, N. Machado, M. I.; Osinaldi, G. M.; Demoliner, A.; Baisch, P. 2005. O impacto industrial na composição química das águas subterrâneas com enfoque de consumo humano (Rio Grande, RS). Química Nova, 28, 5, 788-791. https://doi.org/10.1590/S010040422005000500010

Oliveira, S.; Pasqual, A. 2004. Avaliação de parâmetros indicadores de poluição por efluente líquido de um aterro sanitário. Engenharia Sanitaria e Ambiental, 9, 3, $240-$ $249 . \quad$ https://dx.doi.org/10.1590/S141341522004000300010

Saling, C.; Gräff, A.; Oliveira, E. C.; Böckel, W. J. 2017. Avaliação da qualidade da água de poços rasos no município de Colinas-RS. Tecno-lógica, 21, 2, 59-64. https://dx.doi.org/10.17058/tecnolog.v21i2.7 901

Silva, D. R. R.; Maciel, M. O. S.; Marta, B. B. F.; Bronharo, T. M.; Michelin, A. F. $2018 \mathrm{a}$. Qualidade da água em escolas públicas municipais: análise microbiológica e teor de nitrato em Araçatuba, estado de São Paulo Brasil. Revista do Instituto Adolfo Lutz, 77, el1740, 1-8.

Silva, R. A.; Barbosa, B. G.; Silva, L. R. 2017. Análise microbiológia da água de poços residenciais em Carmo do Rio Verde - GO. REFACER - Revista Eletrônica da Faculdade Evangélica de Ceres, 06, 01, 1-10. https://doi.org/10.36607/refacer.v6i1.3338

Silva, R. S. B.; Sousa, A. M. L.; Sodre, S. S. V.; Vitorino, M. I. 2018b. Avaliação sazonal da qualidade das águas superficiais e subterrâneas na área de influência do Lixão de Salinópolis, PA. Revista Ambiente e Água, 13, 02, 17. https://doi.org/10.4136/ambiagua. 2072

Sousa, C. P. 2006. Segurança alimentar e doenças veiculadas por alimentos: utilização do grupo coliforme como um dos indicadores de qualidade de alimentos. Revista APS, 9, 1, 83-88.

Souza, M. N. A.; Oliveira, C. E. M.; Lezo, A. C.; Pereira, C. S.; Pimenta, L. C. 2014. Presença de bactéria escherichia coli em água proveniente de poços artesianos no município de Fernandópolis - SP. Revista Funec Científica, 02, 03, 46-56.

Thomaz, S. M. 1999. O papel ecológico das bactérias e teias alimentares microbianas em ecossistemas aquáticos. In: Perspectivas da Limnologia no Brasil. $1^{\text {a }}$ ed., Gráfica e Editoria União, São Luís. pp. 147-167.

Tortora, Gerard J.; Funke, Berdell R.; Case, Christine L. 2017. Microbiologia. Artmed, $12^{\mathrm{a}}$ ed.

Zamilian, A. A. E.; Paula, G. P.; Zamilian, J. A. E. 2018. Avaliação microbiológica de águas de poços artesianos em propriedades rurais no município de Colorado do Oeste - Rondônia. Revista Saúde e Desenvolvimento Humano, 06, 03, 101-123. https://dx.doi.org/10.18316/sdh.v6i3.4606 